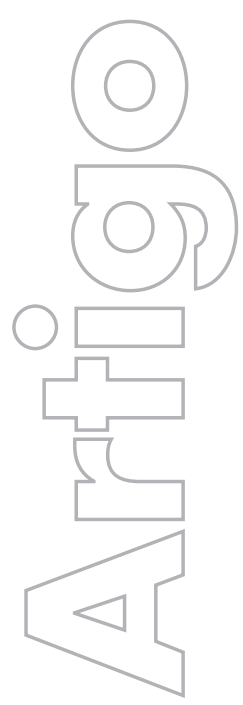

\section{revista}

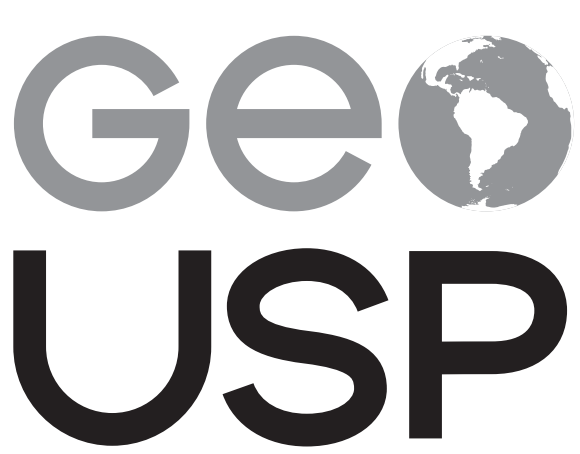

espaço e tempo

Volume 19, no 1 (2015)
Geografia e poesia lírica: considerações sobre a poética do espaço, de Gaston Bachelard

Felipe Cabañas da Silva

FFLCH-USP

p. $060-075$

Disponível em:

http://www.revistas.usp.br/geousp/article/view/80079

Como citar:

SILVA, F. C. Geografia e poesia lírica: considerações sobre $A$ poética do espaço, de Gaston Bachelard. GEOUSP - Espaço e Tempo, São Paulo, v. 19, n. 1, p. 060 - 075, 2015.

\section{$(\boldsymbol{c c c )} \mathbf{E Y}$}

Este artigo está licenciado sob a Creative Commons Attribution 4.0 License. 


\title{
Geografia e poesia lírica: considerações sobre A poética do espaço, de Gaston Bachelard
}

\section{Resumo}

Este artigo procura fazer uma leitura com olhar geográfico da obra $A$ poética do espaço, do filósofo Gaston Bachelard (1993), buscando especificamente identificar suas possíveis contribuições a uma abordagem geográfica da poesia lírica. Considerando que os estudos geográficos da literatura demonstram historicamente uma predileção pelo gênero romanesco (Brosseau, 1996), é importante estender e aprofundar a reflexão sobre outros gêneros literários, entre os quais a poesia lírica. Nesse contexto, é fundamental que se integrem diferentes contribuições teóricas, oriundas de diferentes disciplinas e escolas de pensamento. Questionamos se e como pode o livro do filósofo francês concorrer para se pensarem as relações entre poesia e espaço, entre gênero lírico e geografia, procurando discutir, igualmente, o conceito de topoanálise, que permeia essa importante obra do pensamento fenomenológico. Evidentemente, o artigo não esgota a discussão, complexa, multifacetada e aberta a diferentes abordagens. Espera-se, todavia, que logre demonstrar sua fertilidade.

Palavras-chave: Lírica. Espaço. Bachelard. Poética. Geografia e literatura.

\section{Geography and lyric poetry: reflections on the book The poetics of space, of Gaston Bachelard}

\begin{abstract}
The aim of this article is to realize a geographical reading of the book The poetics of space, written by the philosopher Gaston Bachelard (1993), focusing his potentials contributions to a geographical study of lyric poetry. Considering the fact that the geographical studies of literature historically manifest a predilection for the novel (Brosseau, 1996), it is important to extend and deepen the discussion about other literary genders, including lyric poetry. In this context, the integration of diversified theoretical contributions, derived of various disciplines and intellectual traditions, is very important. We intend to question if and how can the book of the French philosopher contribute to think the relations
\end{abstract}


between poetry and space, lyric and geography, also attempting to discuss the concept of topoanalysis, significant in this important book of the phenomenological thought. Evidently, this article doesn't pretend to exhaust the discussion, complex, multifaceted and opened to different approaches. We intend, however, to demonstrate its fertility.

Keywords: Lyric. Space. Bachelard. Poetics. Geography and Literature.

\section{Geografia e literatura, lírica e geografia}

Desde as últimas décadas do século XX, a geografia vem traçando uma sólida aproximação com a literatura ou, como salienta Suzuki (2010, p. 243), "Os geógrafos têm procurado, há algumas décadas, estabelecer uma densa relação entre a geografia e a literatura", o que resultou em "dissertações de mestrado e teses de doutorado, além de textos apresentados em eventos e capítulos de livros, dentre outras publicações". Inserindo-se no processo de renovação crítica da disciplina e diversificação de metodologias e objetos de pesquisa engendrado sobretudo a partir da década de 1970 - ainda que, como esclarece Brosseau (1996, p. 25), seja possível identificar elementos de uma aproximação entre geografia e literatura desde o início do século XX -, o ramo de estudos tem se enriquecido de um grande número de contribuições e vem dando aportes críticos de inestimável valor à geografia e à crítica literária.

Todavia, subsiste uma questão subjacente aos estudos que inter-relacionam geografia e literatura - ou, como define Lévy (1997, p. 21), "pesquisas geoliterárias" -, que representa considerável desafio para os geógrafos: a questão do gênero literário. Brosseau (1996, p. 25-47) traça um histórico do ramo de pesquisas, e nele podemos identificar uma clara predominância do romance na abordagem geográfica da literatura entre as mais diversas correntes teóricas. Os geógrafos humanistas, por exemplo, "privilegiam o romance na medida em que este parece fornecer-lhes a ocasião ideal de um encontro entre o mundo objetivo e a subjetividade humana" (Brosseau, 1996, p. 33, tradução nossa). Analisando esse contexto, Lafaille (1989, p. 118, tradução nossa) estabelece uma severa crítica:

Submetida a preconceitos humanistas e românticos, a geografia não vê no texto literário mais que um reservatório de imagens geográficas. Semelhante abordagem impõe sérios limites à análise literária em geografia; ela impede, no mínimo, toda relação com o texto poético moderno. A partir das Iluminações, de Rimbaud, primeira manifestação do nonsense na literatura ocidental, ficou comprovado que o que é essencial nesta poesia não é a experiência original da cidade que ela apresenta, mas a transformação radical da função textual que ela opera. Consequentemente, o geógrafo é levado a questionar sua relação com os textos [...]. À parte poucas exceções, os geógrafos confundem a literatura com um meio de informação, com um catálogo de paisagens geográficas, com um documento capaz de esclarecer as atitudes e os valores dos homens e mulheres que habitam o mundo, em suma a literatura é tratada como uma fonte de dados. 
Importante perceber, em ambos os autores, a constatação histórica - importante frisar este termo, uma vez que o presente tem contribuído fortemente para mitigar grande parte dos limites dos estudos - de uma dificuldade da geografia em penetrar os gêneros mais áridos da literatura, aqueles que vão além do registro informativo mais nítido, bem representado pela melhor literatura romanesca de diversos períodos mas não representante do universo literário como um todo.

Os avanços das pesquisas geoliterárias desde a década de 1990 até os dias atuais são notáveis, expandindo o universo de análise e reflexão da geografia. Cabe mencionar brevemente, por exemplo, o trabalho de Bertrand Westphal (2007), La géocritique: réel, fiction, espace. Primeiramente, o autor recupera o caráter simbólico da apropriação do espaço, que traz ao primeiro plano a questão de sua representação. Além do mais, situa seu pensamento no contexto da pós-modernidade, que desestrutura a concepção modernista segundo a qual a teoria (texto) deve refletir a realidade, substituindo-a por uma visão relativa do constructo teórico e, consequentemente, da própria realidade: "Dans ce contexte devenu - ou rendu - mouvant, le rôle des arts qui sont susceptibles d'entretenir avec le monde une relation mimétique revêt une importance nouvelle" (Westphal, 2007, p. 13) - tese interessante, passível de explicar inclusive a intensificação da aproximação entre geografia e literatura, que coincide com o momento histórico da chamada pós-modernidade. Este contexto sugere a possibilidade de uma ficcionalização do real, na teoria, e igualmente de uma realização da ficção. Por isso, Westphal propõe a geocrítica: mais que o estudo da representação do espaço na literatura, esta seria a investigação das relações entre espaço geográfico e espaço literário: "Il s'agira de sonder les espaces humains que les arts mimétiques agencent par et dans le texte, par et dans l'image, ainsi que les interactions culturelles qui se nouent sous leur patronage" (Westphal, 2007, p. 17).

A questão da relação entre real e representação nunca foi tão atual para diversos domínios do saber e o conceito de geocrítica aparece como a tentativa de dar conta dessa atualidade no âmbito do saber geográfico. No que tange à questão da poesia lírica, o conceito de Westphal reconhece um "espaço literário" abrangente, passível de ultrapassar as limitações apontadas por Lafaille e colocar a geografia em relação com a literatura de uma forma mais densa e universal.

Este é um exemplo de trabalho intelectual recente que expande os horizontes do estudo geográfico da literatura. Não obstante, apoiados na análise histórica de Brosseau e na crítica de Lafaille, podemos dizer que o "saldo histórico" mostra ainda uma geografia mais ciosa da informação, do dado, da literatura como transcrição integral de uma experiência geográfica concreta, ou mesmo como descrição fisiográfica pura, e que portanto se aproxima preferencialmente do romance. Nesse sentido, podemos dizer que a verve descritiva da geografia contribuiu sensivelmente para essa conformação dos estudos, uma vez que romance e descrição do espaço encontram-se com certa frequência, sobretudo nas manifestações literárias pré-modernas. $\bigcirc$ que embasa, assim, a tese de que a geografia tende aproximar-se sobretudo do romance é o argumento histórico que, em que pese encontrar-se em vias de superação, ainda coloca obstáculos à análise geográfica da literatura.

A inserção histórica da geografia junto ao saber racionalista-experimental - Corrêa (1980, p. 8) identifica no pensamento geográfico clássico uma "longa tradição conservadora" 
e não podemos esquecer que a disciplina teve forte influência neopositivista durante o século XX - contribui fortemente para esse "saldo" desigual, tendo em vista que, neste contexto, a subjetividade é ofuscada pela sobrevalorização da objetividade e do empirismo. E a literatura pode ser objetiva e empírica, especialmente no romance - preferencialmente realista. ${ }^{1}$ Um outro ingrediente deste contexto é o que poderíamos chamar de uma "tensa relação com o indivíduo", produzida por uma ciência que, naturalmente, inclina-se para o estudo e explicação da totalidade social e não do indivíduo atomizado. Por esses motivos, explica-se a resistência histórica da disciplina em relação às formas literárias em que o mergulho no indivíduo e na subjetividade é mais radical, particularmente a poesia lírica.

Antes de mais nada, cabe-nos uma palavra sobre o que entendemos neste artigo como poesia, poética e lírica, conceitos que o permeiam. Embora seus limites e objetivos não nos permitam nos aprofundar na discussão de cada um dos termos, como seria adequado, é importante ao menos explanar as concepções que nos norteiam. Poesia, aqui, é considerada em sua definição mais elementar, como o gênero literário do verso, pois é neste gênero que a geografia historicamente demonstra mais dificuldade de penetração. Sabemos que mesmo o caráter versífico da poesia é questionável: basta lembrarmos dos poemas em prosa de Baudelaire, Rimbaud e Drummond, por exemplo, para compreendermos que os limites do conceito estão sob tensão, por obra dos próprios poetas em sua busca por liberdade de criação. Por isso, faremos seu uso no estágio mais bruto e mais acessível.

Poética é um termo ainda mais espinhoso. Gledson (1981, p. 12), por exemplo, no estudo "Poesia e Poética de Carlos Drummond de Andrade", considera a poética "uma visão da poesia ou do ofício de ser poeta". Sua tese é a de que Drummond produz poesia pensando sobre ela, ou seja, fazendo poesia e poética simultaneamente. White (1992, p. 169, tradução nossa), por sua vez, sugere que o propósito da poética é "encontrar palavras vivas com as quais proclamar 'a integridade da existência'". No primeiro caso, vemos uma definição que salienta o aspecto formal. No segundo, o aspecto existencial. Este, de fato, é o sentido que mais se aproxima do sentido bachelardiano, onde poética aparece como a possibilidade de uma vivência sensível e subjetiva do espaço. Evidentemente, deveremos, aqui, perseguir o sentido bachelardiano.

Lírica, por sua vez, não é sinônimo de poesia, embora no linguajar comum os dois termos se confundam com certa frequência, mas um tipo de poesia - por isso o uso do epíteto "poesia lírica". Sua definição é controversa, mas é certamente necessário olhar para sua acepção histórica. Segundo Cara (1985, p. 6), na Antiguidade, a lírica é "uma poesia de expressão pessoal, diretamente ligada à música" - o substantivo "lírica" vem de "lira", um instrumento de cordas típico da era antiga. Nesse sentido, a lírica se contrapõe à épica, trazendo a subjetividade individual ao primeiro plano. Rigorosamente, a poesia vem a ser a forma literária do verso, e, nesse caso, a lírica é claramente uma especificidade dessa forma. Uma especificidade que se transformou ao longo do tempo, mas manteve seu elemento central: o eu, o indivíduo.

É da tensão entre indivíduo e totalidade social que Adorno (2003, p. 66), por exemplo, extrai sua concepção de lírica, "uma esfera de expressão que tem sua essência precisamente em não reconhecer o poder de socialização", mas que, contraditoriamente, o carrega:

1 Nesse sentido, o histórico de Brosseau (1996, p. 25-47) mostra uma predominância não só do gênero romance como também da escola realismo nas análises da geografia contemporânea. 
Pois o teor [Gehalt] de um poema não é a mera expressão de emoções e experiências individuais. Pelo contrário, estas só se tornam artísticas quando, justamente em virtude da especificação que adquirem ao ganhar forma estética, conquistam sua participação no universal.

Por isso, a crítica social da lírica deve demonstrar "como o todo de uma sociedade, tomada como unidade em si mesma contraditória, aparece na obra de arte; mostrar em que a obra de arte lhe obedece e em que a ultrapassa" (Adorno, 2003, p. 67). Por essa tensão dialética, o autor acaba por definir a lírica como mergulho radical no eu e extração de uma expressão em forma artística; o eu, todavia, mesmo em sua negação social, não deixa de ser parte integrante da totalidade da sociedade.

Como pode a geografia enfrentar essa tensão, como disciplina sistemática da dimensão espacial da totalidade social, historicamente pouco afeita ao mergulho no indivíduo? Como pode a geografia enfrentar essa tensão visando a extensão dos limites dos estudos geoliterários? É certo que, primeiramente, é preciso buscar referências teóricas que se debrucem sobre a questão. Todavia os limites destas no interior da geografia também são importantes, dada a assimetria entre o contato histórico da disciplina com a prosa e com o verso.

Referências fundamentais para pensar a dialética entre lírica e sociedade são as obras de Theodor Adorno e Walter Benjamin. Do primeiro, a supracitada Palestra sobre lírica e sociedade (2003); do segundo, o sensível estudo Charles Baudelaire: um lírico no auge do capitalismo (2000), em que Benjamin se debruça sobre a obra e a vida do "poeta-símbolo" da modernidade, delas extraindo uma interpretação da relação indivíduo-sociedade e indivíduo-modernidade. Certamente, essas obras são determinantes igualmente para a geografia, uma vez que se reportam à totalidade social, elemento importante da totalidade geográfica, e à modernidade, fenômeno social, histórico e geográfico.

Todavia é de grande valor para a geografia a reflexão mais aprofundada sobre a relação entre seus objetos de estudo e a categoria do espaço, norteadora da disciplina. Neste sentido, cremos ser de grande importância pensar a relação entre espaço e literatura, que se desdobra na relação entre espaço e romance, espaço e conto, espaço e poesia e assim por diante.

Essas referências não devem ser necessariamente exclusivas da geografia, do que é prova o livro Espaço e romance, do crítico literário Antonio Dimas (1994), dedicado a pensar a relação entre o gênero romanesco e a categoria do espaço - mesmo porque a categoria do espaço não é "propriedade" da geografía.

Na busca por referências teóricas que possam orientar a geografia na difícil tarefa de relacionar poesia lírica e espaço geográfico, foi a obra de um filósofo que nos despertou interesse e a disposição de analisar suas contribuições para essa discussão: A poética do espaço, de Gaston Bachelard (1993).

O objetivo deste artigo é, portanto, fazer uma leitura da obra de Bachelard à luz dos desafios colocados aos estudos geoliterários precisamente na questão de sua relação com a poesia lírica, a expressão radical do eu que pressupõe uma relação mais profunda entre sujeito e espaço, demandando a integração de contribuições intelectuais diversificadas. 


\section{A poética do espaço, de Gaston Bachelard}

Primeiramente, cabe deixar claro que não nos aproximamos de Bachelard para sistematizar metodologicamente as relações entre poesia e espaço, por exemplo, porque seu próprio título pressupõe que a matéria não seja essa, senão a filosofia sobre o componente poético da vivência do espaço, ou o que poderíamos chamar "relações entre sensibilidade e espaço", relações evidenciadas por pesquisas geoliterárias que se aproximem do universo lírico.

Podemos dizer que a obra de Bachelard é um tratado sobre o ser, porque mergulha nas entrelinhas da relação psicoemocional, afetiva, sensitiva, estabelecida entre os polos homem-espaço; porém, enfocando esta relação com o espaço íntimo, ou, como diz o filósofo, os "espaços de posse", "espaços defendidos contra forças adversas", "espaços amados", ou ainda "espaços louvados" (Bachelard, 1993, p. 19).

Neste sentido, o filósofo das ciências faz as vezes de poeta: escreve com o vasto estofo intelectual do primeiro e a paixão do segundo. A todo momento oferecendo novos questionamentos suscitados pela riqueza da relação sensitiva entre homem e espaço, $A$ poética do espaço é também uma obra muito importante para o pensamento fenomenológico, no sentido em que apresenta as possibilidades inumeráveis da fenomenologia, tensionando fortemente os limites do pensamento racional. É por isso que, paulatinamente, a leitura da obra nos coloca face às possibilidades de uma "fenomenologia da imaginação" (Bachelard, 1993, p. 2), de uma "fenomenologia microscópica" (p. 4), de uma "fenomenologia do espírito" e "da alma" (p. 4) e, ainda além, de uma "fenomenologia da imagem" (p. 4), de uma "fenomenologia da expressão" (p. 12), "do oculto" (p. 21), "do verbo habitar" (p. 21), "do redondo" (p. 22), "do devaneio" (p. 44), "do ninho real" (p. 107), "da concha habitada" (p. 119), "do verbo sair" (p. 121), "da semeIhança” (p. 158), "do homem da lupa" (p. 164), "do verbo escutar" (p. 186), "do imenso" (p. 190), "do prefixo ex" (p. 200), "da palavra" (p. 201), "do encadeamento das ideias" (p. 237). Com Bachelard, a fenomenologia é efetivamente a ciência das essências dos fenômenos - no limite, todo e qualquer fenômeno, pois, como podemos constatar, o pensador não se furta a sugerir a fenomenologia dos elementos mais surpreendentes.

A primeira questão colocada pelo filósofo diz respeito à imagem poética, que tem uma transubjetividade, isto é, toca profundamente a sensibilidade de diversas consciências. Para compreender essa transubjetividade, sugere ele que "Só a fenomenologia - isto é, a consideração do início da imagem numa consciência individual — pode ajudar-nos a reconstituir a subjetividade das imagens e a medir a amplitude, a força, o sentido da transubjetividade da imagem" (Bachelard, 1993, p. 3, grifos do original). A visão de uma imagem poética transubjetiva sintoniza-se com as considerações de Adorno sobre a impossibilidade de separação entre o individual e o universal na expressão poética.

Assim, o filósofo define sua poética do espaço como pesquisas "sobre a imaginação poética", a produção (naturalmente intersubjetiva) de imagens poéticas; e, muito importante, sua repercussão na alma. "Já não a tomamos [a imagem poética] como um 'objeto'. Sentimos que a atitude 'objetiva' do crítico abafa a 'repercussão' [intersubjetiva], rejeita, por princípio, essa profundidade onde deve ter seu ponto de partida o fenômeno poético primitivo" (Bachelard, 1993, p. 8). 
As considerações fenomenológicas têm um papel central na obra, uma vez que o autor se afasta da objetividade, critica reiteradamente o racionalismo, e seu estudo da "imaginação poética" se desenvolve sobre inequívocas bases fenomenológicas. Nesse ponto, identifica-se igualmente sua pertinência à pesquisa geoliterária, já que o estudo da literatura no âmbito da geografia esteve fortemente associado a diferentes correntes de inspiração fenomenológica. $\bigcirc$ mais importante, porém, é que o estudo de Bachelard não é da imaginação poética como um todo, mas da imaginação poética do espaço:

No presente livro, nosso campo de exame tem a vantagem de ser bem delimitado. Isso porque pretendemos examinar imagens bem simples, as imagens do espaço feliz. Nessa perspectiva, nossas investigações mereceriam o nome de topofilia. Visam determinar o valor humano dos espaços de posse, dos espaços defendidos contra forças adversas, dos espaços amados. $\bigcirc$ espaço percebido pela imaginação não pode ser o espaço indiferente entregue à mensuração e à reflexão do geômetra. É um espaço vivido. E vivido não em sua positividade, mas com todas as parcialidades da imaginação (Bachelard, 1993, p. 19, grifos do original).

Curioso é nos depararmos com o conceito de topofilia, tão associado na geografia ao pensamento de Tuan (2012, p. 135-136), que define topofilia como "todos os laços afetivos dos seres humanos com o meio ambiente material", definição que se aproxima da de Bachelard. Além do mais, encontramos a ideia de "espaço vivido", muito próxima à de "mundo vivido", conceito oriundo de Edmund Husserl que é central para a geografia humanista de inspiração fenomenológica.

Nessa fenomenologia da imaginação do "espaço feliz", são os pequenos espaços da vida íntima - aqueles historicamente vistos como secundários pela investigação geográfica, sempre centrada na macroinvestigação espacial - que passam pelo crivo do filósofo. Assim, mergulha na casa e seus elementos: o porão, o sótão; pensa o sentido da cabana, as gavetas, os cofres, os armários; dedica-se a refletir sobre os cantos, a miniatura, o redondo; traz à tona a relação de ninho ou concha que o homem parece estabelecer com determinados espaços.

A essa "fenomenologia dos espaços íntimos", Bachelard (1993, p. 28) vem a chamar de topoanálise, ou, em suas palavras, "o estudo psicológico sistemático dos locais de nossa vida íntima". Sabemos que a experiência humana do mundo é espaço-temporal, o que é observável na vida social, como indicam historiadores, geógrafos e sociólogos. Bachelard demonstra que a dialética espaço-tempo também se faz presente na vida íntima e na relação sensível com seus espaços:

Nesse teatro do passado que é a memória, o cenário mantém os personagens em seu papel dominante. Por vezes acreditamos conhecer-nos no tempo, ao passo que se conhece apenas uma série de fixações nos espaços da estabilidade do ser, de um ser que não quer passar no tempo; que no próprio passado, quando sai em busca do tempo perdido, quer "suspender" o voo do tempo. Em seus mil alvéolos, o espaço retém o tempo comprimido. É essa a função do espaço [...]. Aqui o espaço é tudo, pois o tempo já não anima a memória. A memória - coisa estranha! - não registra a duração concreta, a duração no sentido bergsoniano. 
Não podemos reviver as durações abolidas. Só podemos pensá-las, pensá-las na linha de um tempo abstrato privado de qualquer espessura. É pelo espaço, é no espaço que encontramos os belos fósseis de duração concretizados por longas permanências (Bachelard, 1993, p. 28-29).

Para o filósofo, portanto, o conhecimento do ser no tempo é na realidade "uma série de fixações nos espaços da estabilidade do ser", que são fundamentalmente os "espaços da intimidade". O espaço retém o tempo, como nas rugosidades de Santos (2004a, p. 140), aquilo "que fica do passado como forma, espaço construído, paisagem, o que resta do processo de supressão, acumulação, superposição, com que as coisas se substituem e acumulam em todos os lugares". Em ambas as concepções, a compreensão do espaço ultrapassa largamente o "espaço do geômetra", incorporando a dimensão histórica e simbólica. $\bigcirc$ espaço de Santos (2004b, p. 9), "acumulação desigual de tempos", produz rugosidades, ou os alvéolos bachelardianos, que retêm o "tempo comprimido".

De qualquer maneira, o espaço é fundamental em cada página dessa significativa obra de filosofia poética. Espaço como dimensão da fenomenologia do ser, essencialmente independente de uma discussão dimensional, mas eminentemente focado nos pequenos espaços, nos espaços da segurança, na morada que faz as vezes de "ninho" do homem, onde se realiza plenamente ou não a "função de habitar" (Bachelard, 1993, p. 37/43), para depois atingir o universo.

A casa, neste sentido, desempenha um papel crucial na sensível relação afetiva do ser com seu espaço. Porque o espaço é sobremaneira um espaço habitado: o homem não habita somente a sua casa, o seu "ninho"; o homem habita efetivamente o mundo, isto é, sua experiência delimita diferentes níveis de apropriação do espaço, que, entretanto, se iniciam com a plenitude da habitação de uma casa, de uma morada, núcleo da "intimidade protegida":

É preciso dizer como habitamos o nosso espaço vital de acordo com todas as dialéticas da vida, como nos enraizamos, dia a dia, num "canto do mundo". Porque a casa é o nosso canto do mundo. Ela é, como se diz amiúde, o nosso primeiro universo. É um verdadeiro cosmos. [...] Os verdadeiros pontos de partida da imagem, se os estudarmos fenomenologicamente, revelarão concretamente os valores do espaço habitado, o não-eu que protege o eu. [...] Todo espaço realmente habitado traz a essência da noção de casa (Bachelard, 1993, p. 23-25).

A relação se reproduz, tendo o ser como núcleo. Diversos elementos da relação do homem com o espaço não traduzem precisamente essa transposição da função de habitar, que começa na morada e se estende ao mundo, que começa no interior (a casa como extensão do interior do ser, o "não-eu" que protege o eu) e se transpõe ao exterior (o mundo para além da casa, o mundo compartilhado)?

○ espaço "sagrado" da intimidade protegida é compartimentado em outros, menores, mas não menos significativos; o filósofo estabelece uma fenomenologia de todos eles, encontrando seu componente afetivo e seu componente simbólico. Demonstra psicanaliticamente, 
assim, o significado do porão e do sótão. Segundo Bachelard, "A casa é um corpo de imagens que dão ao homem razões ou ilusões de estabilidade". Assim, podemos imaginá-la como um ser vertical, que se eleva:

A verticalidade é proporcionada pela polaridade do porão e do sótão. As marcas dessa polaridade são tão profundas que, de certo modo, abrem dois eixos muito diferentes para uma fenomenologia da imaginação. Com efeito, quase sem comentário, pode-se opor a racionalidade do teto à irracionalidade do porão. [...] Os geógrafos sempre mencionam que em cada país a inclinação do teto é um dos sinais mais seguros do clima. "Compreende-se" a inclinação do teto (Bachelard, 1993, p. 36).

O porão, em contrapartida, "é a princípio o ser obscuro da casa, o ser que participa das potências subterrâneas. Sonhando com ele, concordamos com a irracionalidade das profundezas" (Bachelard, 1993, p. 37).

Por essas considerações, percebemos quão sensível é a visão do filósofo que, em diversos momentos de sua obra, lança mão das teorias psicológicas e psicanalíticas. Percebemos também a importância que ele atribui ao componente simbólico dos espaços da intimidade, sempre tendo a imaginação poética como material de trabalho.

A casa, assim, faz-se universo - um universo íntimo -, com áreas de segurança (teto/ sótão) e mistério, medo (porão). Assim, o universo "interior-exterior" que é a casa é segmentado em outros universos íntimos: cantos, gavetas, cofres, armários, fechaduras. Qual seria a importância espiritual desses microespaços usualmente tidos como absolutamente irrelevantes na perspectiva de uma macroanálise geográfica?

Com o tema das gavetas, dos cofres, das fechaduras e dos armários, vamos retomar contato com a insondável reserva dos devaneios de intimidade. $\bigcirc$ armário e suas prateleiras, a escrivaninha e suas gavetas, o cofre e seu fundo falso são verdadeiros órgãos da vida psicológica secreta. Sem esses "objetos" e alguns outros igualmente valorizados, nossa vida íntima não teria um modelo de intimidade. São objetos mistos, objetos-sujeitos. Têm, como nós, por nós e para nós, uma intimidade (Bachelard, 1993, p. 91).

Podemos perceber que o espaço é aqui um valor humano acima de tudo, um elemento inseparável da constituição da totalidade do ser, verdadeiro alicerce de sua estrutura biopsíquica - uma visão sensível que, cuidadosamente interpretada, vai muito além de uma metafísica estéril, auxiliando na compreensão, por exemplo, de que a negação social da "função de habitar", desse espaço de intimidade constitutivo de indivíduos física e psicologicamente saudáveis, tem sempre consequências trágicas.

Por essas considerações, entende-se também que não é um acaso que a obra do filósofo francês esteja permeada do início ao fim pela obra dos grandes poetas e escritores. $\bigcirc$ autor considera que "há sentido em dizer que se 'lê uma casa', que se 'lê um quarto', já que quarto e casa são diagramas de psicologia que guiam os escritores e os poetas na análise da intimidade" 
(Bachelard, 1993, p. 56). Assim, o filósofo dialoga fartamente com a literatura universal, com nomes como Charles Baudelaire, Henri Bachelin, Rainer Maria Rilke, Henri Bosco, Henry David Thoreau ou Jules Supervielle.

Em relação aos poetas, sobretudo, sua relação com os espaços da intimidade costuma ser perene e densa. E, também neste aspecto, a consideração de Adorno é pertinente: a lírica extrai da individuação o universal, da intimidade o público, do interior o exterior. A rica relação que o poeta estabelece com o espaço, assim, começa nos espaços da intimidade, o que torna as obras líricas um fértil terreno para o desenvolvimento da topoanálise bachelardiana.

No Brasil, podemos nos referir à obra de Carlos Drummond de Andrade, lembrando, por exemplo, que a quarta seção do livro Boitempo II: menino antigo, dedica-se inteiramente a uma poética da casa, poética nostálgica da casa que tudo indica ser o lar senhorial da familia fazendeira, seção que tem como título - de inegável tom bachelardiano - "Morar nesta casa" (Drummond de Andrade, 2006). O primeiro poema dessa seção é paradigmático:

Há de dar para a câmara,

de poder a poder.

No flanco, a Matriz,

de poder a poder.

Ter vista para a serra,

de poder a poder.

Sacadas e sacadas

comandando a paisagem.

Há de ter dez quartos

De portas sempre abertas

ao olho e pisar do chefe

Areia fina lavada

na sala de visitas.

Alcova no fundo

sufocando o segredo

de cartas e baús

enferrujados.

Terá um pátio

quase espanhol vazio

pedrento

fotografando o silêncio

do sol sobre a laje,

da família sobre o tempo.

Forno estufado

fogão de muita fumaça

e renda de picumã nos barrotes.

Galinheiro comprido

à sombra de muro úmido. 


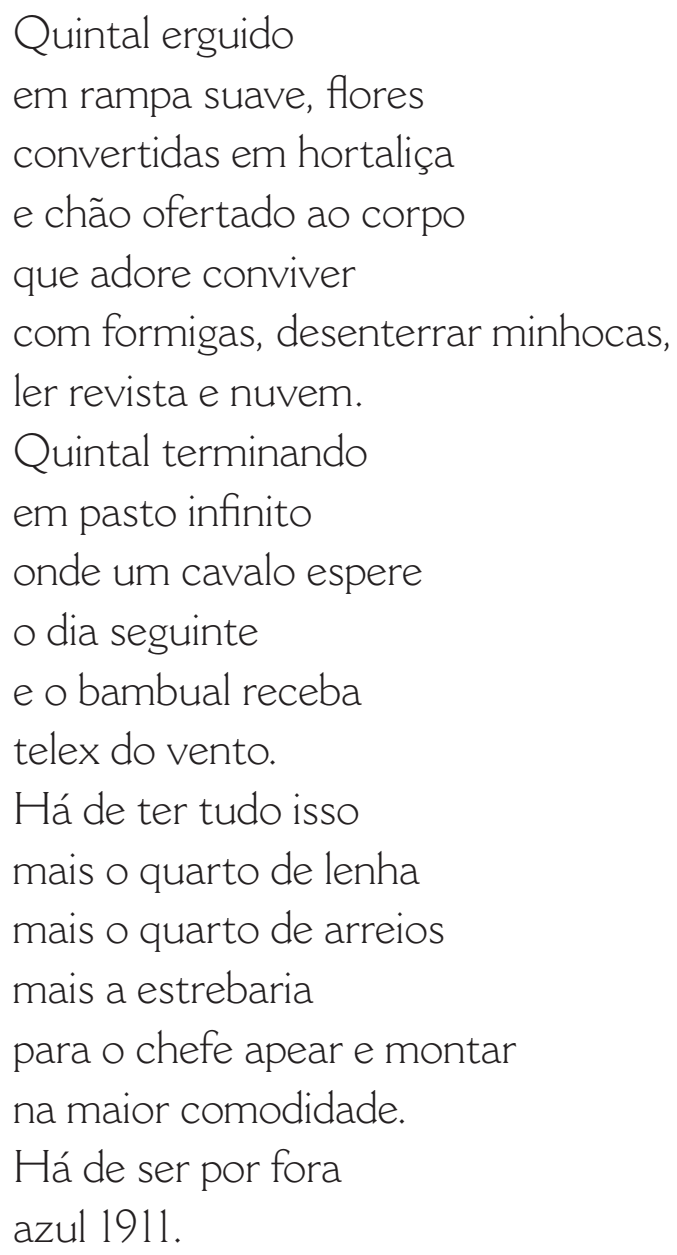

Do contrário não é casa (Drummond de Andrade, 2006, p. 99-100).

Esse livro de Drummond é de 1973, e nele um poeta já septuagenário revisita a infância, o ambiente de sua formação, de sua juventude e adolescência, a Fazenda do Pontal, onde passa parte da infância, a residência da familia em Itabira, as relações sociais e as heranças históricas de seus espaços de origem. Nesse poema, o eu lírico revela o que parece ser a casa de sua família em Itabira. Da configuração do espaço físico dessa casa, deriva-se um ideal de todas as casas - nas entrelinhas, diz-nos o poema: "toda casa há de ser como esta, do contrário não é casa".

De um ponto de vista bachelardiano, vemos como é significativo o mergulho nos espaços da intimidade, como é lírica e poética esta relação, procurando expor e guardar cada porta, cada cômodo e até mesmo os objetos, cartas e baús, o pátio, o galinheiro, o quintal com seus recantos e mistérios, seus bichos e flores, e até mesmo a tinta que adorna a construção, "azul 1911", que contribui para conformar o que Bachelard chama de "primeiro universo" do ser. Isto é importante em Drummond por estarmos diante de um poeta de fortes tintas sociais - como afirma Candido (2011, p. 85), o maior poeta social da literatura brasileira contemporânea - e que estabeleceu uma densa relação lírica com seus espaços de vivência - o Rio de Janeiro, sobretudo na fase de maior intensidade social de sua lírica, a primeira metade da década de 1940, quando publica "Sentimento do Mundo" e "A rosa do povo", e Itabira, em todas as fases, mas sobretudo quando revisita o passado na série "Boitempo". Neste poema, mostra-se claramente, em Drummond, a possibilidade de uma topoanálise de sentido bachelardiano, ou seja, de estudo psicológico dos espaços íntimos. 
que intentamos aqui, entretanto, não é resenhar o livro de Bachelard ou esgotar a compreensão dessa obra densa, mas discutir os pontos que acreditamos mais pertinentes à investigação geográfica da literatura, especialmente da expressão lírica. A principal questão que permeia este artigo é: que contribuições pode dar a obra de Bachelard aos geógrafos que pretendem relacionar lírica e geografia?

Neste sentido, procuramos demonstrar alguns pontos nevrálgicos da obra, que sugerem caminhos interessantes de investigação. Gostaríamos, agora, de desenvolver uma reflexão crítica sobre o conceito de topoanálise, um dos mais importantes temas da obra, considerando especialmente suas possíveis contribuições aos estudos geoliterários da lírica. Em seguida, em nossas Considerações Finais, estabeleceremos uma visão crítica geral sobre a obra e seus possíveis aportes.

\section{Uma análise crítica do conceito de topoanálise}

Qual a importância de um conceito como o de topoanálise para os estudos geoliterários, sobretudo aqueles focados na relação entre lírica e espaço geográfico? Primeiramente, é necessário lembrar que Bachelard (1993, p. 28) define topoanálise como "o estudo psicológico sistemático dos locais de nossa vida íntima"; ou, em outra tradução, "o estudo psicológico sistemático dos lugares físicos de nossa vida íntima" (Bachelard, 1978, p. 202). Interessante perceber a notável diferença entre as duas traduções, mas de todo modo fica clara a proposta de estudo dos espaços onde se estabelece a intimidade.

$\bigcirc$ problema do conceito para a geografia reside justamente no seu traço íntimo. $\bigcirc$ filósofo propõe um conceito que estruture o estudo do que poderíamos chamar uma "geografia da intimidade". Porém, a preocupação central da geografia historicamente não são os espaços da intimidade, mas os espaços da sociabilidade.

A partir do pensamento de Gaston Bachelard, podemos desenvolver uma série de reflexões importantes sobre algumas das tendências humanas de relação com o espaço, sobretudo se considerarmos que várias das tendências afetivas que se estabelecem nos espaços íntimos se reproduzem nos espaços sociais. Além do mais, a obra do filósofo é prolífica em associações literárias, mas fica claro que ele não pensou seu conceito com a preocupação centrada nos espaços da sociabilidade; portanto, só secundariamente se pode associá-lo a ela a partir dessa conceituação. Provavelmente por isso Borges Filho (2008) propõe estender a definição para o estudo do espaço na obra literária, argumentando que:

Apesar de aceitarmos a sugestão de Bachelard em relação à terminologia, divergimos do pensador francês em relação à definição. Por topoanálise, entendemos mais do que o "estudo psicológico", pois a topoanálise abarca também todas as outras abordagens sobre o espaço. Assim, inferências sociológicas, filosóficas, estruturais etc., fazem parte de uma interpretação do espaço na obra literária. Ela também não se restringe à análise da vida íntima, mas abrange também a vida social e todas as relações do espaço com a personagem seja no âmbito cultural ou natural. 
Teríamos assim um conceito mais abrangente, englobando a relação do espaço como um todo com a "obra literária" como um todo, mas, sobretudo, estendendo sua definição do íntimo ao social, do micro ao macro, do interior ao exterior, "todas as relações do espaço com a personagem seja no âmbito cultural ou natural". Certamente, colocado assim, o conceito de topoanálise acaba por ganhar um alcance maior, tendendo a ser bem recebido entre os geógrafos (embora Borges Filho seja um crítico literário) estudiosos da literatura.

A questão que se faz necessária, no entanto, é: definindo topoanálise como o estudo do espaço na obra literária, este nível de abrangência não acaba por confundir o conceito e a área de estudos? Pois "o estudo do espaço na obra literária" não são as próprias "pesquisas geoliterárias" de que fala Lévy? Além do mais, como "estudo do espaço na obra literária", podemos pensar em chamar as "pesquisas geoliterárias" de "geografia da literatura" ou "geografia literária" - acrescentando a esta hipotética disciplina o "estudo da obra literária no espaço". Neste caso, o conceito de geocrítica, de Westphal, parece mais coerente.

Evidentemente, Bachelard, crítico vigoroso do racionalismo e do positivismo, respeitava a abrangência dos conceitos. É possível identificar a possibilidade de abertura em sua concepção de topoanálise. E, também em sua concepção, um interesse geográfico. Porém, vemos que com fins "operacionais", isto é, visando uma aplicação prática nos estudos geoliterários, o conceito bachelardiano demanda algum grau de extrapolação em relação a sua formulação original.

No que tange especificamente à relação entre lírica e espaço geográfico, os principais questionamentos suscitados pela topoanálise permanecem. A profundidade filosófica e sensível de Bachelard o leva a esquadrinhar a obra de grandes poetas da literatura universal em busca da fundamentação do estudo dos espaços íntimos, identificando núcleos psicoemocionais comuns, que enriquecem sua fenomenologia da relação entre o ser e os lugares físicos da intimidade. Porém, esta é ainda uma topoanálise que se esgota no íntimo e não alcança o espaço social, o que exige a mesma adaptação do conceito se almejarmos a fundamentação da relação entre lírica e espaço social.

Talvez essas necessidades encaminhem os geógrafos para uma nova definição do conceito de topoanálise - o que faz Borges Filho, provavelmente atendendo às necessidades dos críticos, mas de forma pertinente à geografia. De qualquer maneira, a topoanálise bachelardiana deve ser considerada uma referência valiosa para os estudos geoliterários, uma vez que trata essencialmente da relação sensível com o espaço. Podemos dizer que a topoanálise do filósofo francês ocupa-se da relação sensível com o espaço íntimo, ou "microespaço", enquanto as pesquisas geoliterárias se ocupam da relação sensível com os espaços sociais, ou "macroespaços". Como se encontram essas sensibilidades? Essa é uma questão que merece ser mais bem desenvolvida no âmbito da geografia.

\section{Considerações finais}

Procuramos discutir as contribuições da obra A poética do espaço, de Gaston Bachelard, aos estudos geoliterários, especialmente os que se debruçam sobre a poesia lírica. Fundamentados no histórico de estudos estabelecido por Brosseau (1996), argumentamos que as pesquisas dedicadas à poesia são minoritárias, uma vez que, como sustenta Lafaille (1989), os geógrafos tendem a ver a literatura como um registro de dados sobre o espaço, forma literária mais distante da poesia - sobretudo a moderna. 
É preciso ultrapassar essa visão limitada de literatura e alargar os horizontes dos geógrafos que se dedicam a pensar a relação entre espaço e arte literária. É preciso adentrar a discussão dos gêneros literários e compreender suas especificidades, relacionando-as à geografia. Para tanto, é preciso dialogar com referências teóricas diversificadas, que contribuir, direta ou indiretamente, com essa discussão.

É nossa opinião, como é também a de Lafaille, que, integrada às pesquisas geoliterárias, a lírica (especialmente a moderna) pode dar contribuições importantes aos estudos geográficos. Para Lafaille (1989, p. 119), essas contribuições consistem sobretudo em engendrar a reflexão crítica, ultrapassando as limitações de uma mera relação informativa sobre o espaço físico e humano.

A aproximação com a obra de Gaston Bachelard pretendia buscar referências teóricas que fundamentassem ou enriquecessem as reflexões sobre poesia lírica e geografia. Tendo em mente que a lírica é historicamente um tema externo ao pensamento geográfico, é importante que os geógrafos dialoguem com referências teóricas externas - a filosofia e a crítica literária tendem a ser excelentes interlocutoras, dada sua tradição na abordagem da questão. Por isso, consideramos importante ler A poética do espaço no âmbito das pesquisas geoliterárias, especialmente das que visam pensar as relações entre poesia lírica e espaço.

Evidentemente, este artigo não pretende esgotar a leitura dessa densa obra da filosofia universal, mas dela oferecer uma leitura que eventualmente aguce o interesse de outros geógrafos. Finalmente, condensamos nossa leitura em alguns pontos de destaque, esperando que eles ajudem a esclarecer o interesse da obra do ponto de vista geoliterário.

(1) Não se deve buscar na obra de Bachelard uma sistematização metodológica das relações entre poesia e espaço ou entre literatura e espaço. Para o autor (1993, p. 145), a sistematização metodológica estaria mais próxima daquilo que ele imagina para um "espírito positivo". Bachelard nos convida a uma peregrinação intelectual pelos espaços da intimidade, peregrinação quase sem rédeas, usufruindo da grande liberdade de um pensamento fenomenológico reiteradamente crítico das limitações racionalistas. Entretanto, mesmo sem ambicionar essa sistematização, a obra do filósofo acaba oferecendo inúmeros caminhos para inquirir a literatura e o espaço, tão mais interessantes quanto mais seja o leitor tributário de uma fenomenologia que poderíamos chamar "radical". Em grande parte da obra, o filósofo mostra tamanho respeito aos poetas que parece dizer-nos para lhes dar mais voz. Ouvir mais os poetas para compreender a relação sensível com o espaço: eis uma postura bachelardiana que, embora não apareça como tal, pode tomar a forma de um verdadeiro paradigma, uma vez que denota imenso respeito pela voz e imanência das próprias obras literárias, o que pode ajudar geógrafos ou cientistas sociais em geral a não se aproximarem de obras literárias munidos de preconcepções disciplinares limitantes.

(2) A obra bachelardiana deixa claro que, na relação sensível com o espaço, nenhuma escala deve ser desprezada. Atribuir importância ao espaço de uma gaveta pode parecer absurdo na perspectiva de uma totalidade social contraditória, que já coloca suficientes desafios à compreensão dos intelectuais, com múltiplas questões fundamentais e de intrincada possibilidade de resolução. Claramente, não é esse tipo de espaço que deve concentrar a atenção dos geógrafos, mas devemos ter em mente que, no pensamento de Bachelard, não é o espaço da 
gaveta que é evidenciado, mas o ser que se relaciona com esse espaço. Nesse sentido, a gaveta tem importância como elemento da psicologia do ser e, assim, evidencia-se a significativa relação simbólica e afetiva que intervém nas dimensões aparentemente mais ínfimas. Que o pensamento do filósofo se esgote nesses espaços é um problema na perspectiva de um pensamento geográfico cioso de sua macrofunção. Mas não deveríamos também considerar um problema que as análises geográficas se esgotem no espaço social e só raramente adentrem os espaços íntimos? Talvez a maior contribuição da obra de Bachelard para a geografia seja justamente esta: reconhecer a importância psicológica do espaço íntimo.

(3) A poética do espaço demonstra o vigor do pensamento fenomenológico na consideração da relação sensível com o espaço e na abordagem sensível da literatura para a compreensão dessa relação. Essa constatação é importante para a geografia, uma vez que a literatura no âmbito da disciplina desperta maior interesse entre as correntes de inspiração fenomenológica. Essa questão merece atenção e mais estudos por parte dos geógrafos, visando compreender a conexão entre geografia, literatura e fenomenologia.

(4) Encontramos em Gaston Bachelard uma menção ao conceito de topofilia, essencial na obra de Yi Fu Tuan (um dos maiores expoentes da geografia humanista, corrente de grande inspiração fenomenológica) e que abre extensas possibilidades de abordagem na relação afetiva entre os seres humanos e "o meio ambiente material" (Tuan, 2012, p. 135-136) - que compreende, bem entendido, o espaço humano e o espaço físico. Qual a relação entre a ideia de topofilia em Gaston Bachelard e a formulação do conceito de Yi Fu Tuan? Essa é outra questão suscitada pela obra que merece estudo mais cuidadoso e pode ajudar a esclarecer a pertinência do pensamento de Bachelard para a geografia contemporânea.

(5) $\bigcirc$ conceito de topoanálise pode ser de grande valor para os estudos geoliterários, e mesmo para os estudos geográficos como um todo, uma vez que coloca em questão a relação sensível com o espaço, crescentemente objeto de preocupação da geografia. De fato, a formulação de um conceito de caráter estrutural daria mais solidez aos estudos geoliterários, concorrendo para a construção de um estatuto teórico-metodológico mais bem delimitado e para uma maior unificação de ideias e procedimentos. Entretanto, tal como é formulado por Bachelard, o conceito precisa ser extrapolado para cumprir semelhante função junto ao pensamento geográfico ou no âmbito da crítica literária. Como, exatamente, os geógrafos podem trabalhar sobre o conceito de topoanálise como formulado por Bachelard e como podem extrapolá-lo, sem deformar o pensamento do filósofo? Essa é outra questão que merece desenvolvimento. Esperamos ter contribuído, ao menos, para enriquecer alguns debates que têm intensificado sua importância para a geografia contemporânea.

\section{Referências}

ADORNO, T. W. Notas de literatura I. São Paulo: Duas Cidades/Editora 34, 2003.

BACHELARD, G. A poética do espaço. São Paulo: Martins Fontes, 1993.

Coleção Os pensadores. São Paulo: Abril Cultural, 1978.

BENJAMIN, W. Charles Baudelaire: um lírico no auge do capitalismo. 3. ed. São Paulo: Brasiliense, 2000. 
BORGES FILHO, O. Espaço e literatura: introdução à topoanálise. In: CONGRESSO INTERNACIONAL DA ASSOCIAÇÃO BRASILEIRA DE LITERATURA COMPARADA, XI, 2008, São Paulo. Anais eletrônicos. São Paulo: Abralic, 2008. Disponível em: $<$ http://www.abralic.org.br/download/anaiseventos/cong2008/ AnaisOnline/simposios/ pdf/067/OZIRIS_FILHO.pdf>. Acesso em: 13 jan. 2015

BROSSEAU, M. Des romans géographes. Paris: L'Harmattan, 1996.

CANDIDO, A. Inquietudes na poesia de Drummond. In: Vários escritos. 5. ed. Rio de Janeiro: Ouro sobre Azul, 2011. p. 69-99.

CARA, S. A. A poesia lírica. São Paulo: Ática, 1985.

CORREAA, R. L. Da nova geografia à geografia nova. Revista de Cultura Vozes, Petrópolis, v. 74, p. 5-12, 1980.

DIMAS, A. Espaço e romance. 3. ed. São Paulo: Ática, 1994.

DRUMMOND DE ANDRADE, C. Boitempo: menino antigo. 8. ed. Rio de Janeiro: Record, 2006.

GLEDSON, J. Poesia e poética de Carlos Drummond de Andrade. São Paulo: Duas Cidades, 1981.

LAFAILLE, R. Départ: Géographie et poésie. The Canadian Geographer/Le Géographe canadien, v. 33, n. 2, p. 118-130, 1989.

LÉVY, B. Géographie culturelle, géographie humaniste et littérature: Position épistémologique et méthodologique. Géographie et Cultures, n. 21, p. 27-44, 1997.

SANTOS, M. A natureza do espaço. 4. ed. São Paulo: Edusp, 2004a.

Pensando o espaço do homem. 5. ed. São Paulo: Edusp, 2004b.

SUZUKI, J. C. O poeta, a cidade e o esfacelamento do indivíduo na modernidade: uma leitura de "A rosa do povo". In: MARANDOLA JR., E.; GRATÃO, L. H. B. Geografia e literatura: ensaios sobre geograficidade, poética e imaginação. Londrina: Eduel, 2010. p. 243-256.

TUAN, Y. F. Topofilia: um estudo da percepção, atitudes e valores do meio ambiente. Londrina: Eduel, 2012.

WESTPHAL, B. La géocritique: réel, fiction, espace. Paris: Éditions de Minuit, 2007.

WHITE, K. Elements of geopoetics. Edinburgh Review, n. 88, p. 163-178, 1992. 